\title{
Division of Nurse Staffing and Compromised Patient Care
}

\author{
Komal Abdul Rahim* \\ Nurse Intern, the Aga Khan University Hospital, Hospital in Karachi, Pakistan \\ *Corresponding Author \\ Komal Abdul Rahim
}

\section{Article History}

Received: 21.12 .2020

Accepted: 07.01.2021

Published: 20.01.2021

Nurses are always expected to deliver care with full compassion. They are obliging to fulfill their responsibilities in every circumstance, but, what if they do not care for the patients who are not assigned to them?

During our Leadership and management clinical rotation in C1 ward of a tertiary care hospital, I was on a round with our Head Nurse in the semi-private area where I, myself observed the scenario mentioned above. While on a round, I observed that there are three service lines in C1 unit altogether: Neurology, Orthopedic and ENT. Because of the distinctness of each service lines, the staff assigned to these specified beds are also different. For example, if there are six beds of ENT in semi-private area, the staff assigned to them will look after those six beds only, and not the other beds of other service line. In a moment, patient on one of the beds from ENT pressed the call bell for the nurse. The staff of ENT was not present there at that moment, and surprisingly, no other staff from Neurology or Orthopedic attended the call bell despite of the fact that they saw the light alarming for the call from the patient. I said to the Head Nurse that the patient has pressed the call bell, and she replied: "You can also go to attend the bell". I stepped my foot forward, but in the meantime, the ENT staff came in and attended the bell. The Head Nurse approach was very much correct for me, as she gave prompt response on a situation by asking us to attend the call bell.

This thing just blew our mind that because of the presence of three service lines in one area, there is a clear cut division of the staff who are very much particular about their assigned beds. Well managed staffing of nurses is very much important in a healthcare system [1]. If it is mismanaged, it is the patient who suffers and gets compromised in their care. It is important to consider the nurse-to patient ratio. This is because; it is directly linked with nursing workload and the quality of patient's health outcomes [2]. In order to combat this, it is significant to consider adequate nurse staffing per shift which is only possible when there is a proper coordination between the nursing staff and the management as per bedside acuity of patients or turnovers [2], the presence of supporting staff and other factors.

Kim, Yoo and Soe [3] proposed that it is the unit working environment and policies that lead to missed nursing care. It is being noted that because of the workload in the unit, the nurses neglect to attend the patients of the fellow nurses. However, if they go to attend the bell of the unassigned patient, they just inform that your nurse will come to see you in a couple of minutes. Rather, the nurse should ask the patient about their concern. The patient might only have called the nurse for simple work like to detach the IV line so that he can go to washroom. However, if the patient is concerned to change his medication, the unassigned nurse can excuse the patient to wait for the assigned nurse to minimize the chances of medication error as that nurse is better aware about the medications given to the patients of their specialty.

A qualitative study was conducted by Kieft et al. [4] where they interviewed 6-7 Dutch Registered Nurses in four focus group discussion to identify factors that leads to positive patient outcomes. Following were the aspects they highlighted were significant for positive outcomes: "clinically competent nurses, collaborative working relationships, autonomous nursing practice, adequate staffing, and control over nursing practice, managerial support and patientcentered culture". It is important to note that they collaborative working relationships as one of the aspects, which means that if you have a supportive nursing fellows around, this will eventually lead to quality patient care. Alongside, other factors highlighted are also important to consider. On the contrary, if there are not sufficient nurses, it will lead to negative patient's outcomes. Inadequate nursing staff is directly related to increased patient mortality [5]. An addition of one RN (full time) per 1000 inpatient days decreases the mortality of patients up to $4.3 \%$, whereas shortage of nurses leads to $2-7 \%$ chances of patient's mortality [5].

Copyright (C) 2021 The Author(s): This is an open-access article distributed under the terms of the Creative Commons Attribution 4.0 International License (CC BY-NC 4.0) which permits unrestricted use, distribution, and reproduction in any medium for non-commercial use provided the original author and source are credited. 
Why the fellow nurses are so reluctant to help others? This is because they are burdenized by their own responsibilities. This leads to burnout amongst the nurses whose one grass root cause could be increased nurse-patient ratio [6]. These work related stress are defined as "emotional exhaustion, depersonalization and personal accomplishments" [7]. As a result, the nurses start leaving their job. Gutsan et al. [6] mentioned in his article that the turnover rates of CNAs, RNs and LPAs are $75 \%, 56 \%$ and $51 \%$ which in turn increases the demands of nurses in the hospitals leading to burnout in the current nursing staff working and this cycle goes on.

If we look back to our issue, I believe that it is the management issue because it is them who has to look for better collaboration between nurses of different service lines working in a same unit. A research was conducted in Korea which identifies the ability of the Nurse Manager leadership as one of the factor in missed nursing care [3]. This study suggests that it is the management responsibility to handle the nurses. In our case also, it is the Head Nurse who can resolve this issue because she can apply the authoritarian leadership style in this case. According to Registered Nurses' Association of Ontario [8] "An understanding of the relationships between system inputs, throughputs, and outputs can lead to a better understanding of how factors in the work environment affect clinical outcomes on nursing units" (p.31). Nurses being the asset (input) of the organization are in the key role to practice standardize care (throughput) to ensure client's timely fulfillment of need and satisfaction (output).

Whenever the Head Nurse encounters such scenarios, she can apply the situational theory of leadership to handle things as per the context [9]. In our case, transformational leadership style was applicable. She knew that I was on our LM rotation, and were not there to engage in care, she put patient's care as the first priority and asked us to way in. This leadership style finds its roots in building motivation and relationship of staff members for a common vision of the organization.

In order to resolve this issue, the Head nurse should pay attention to these small missed care aspects when doing a round in a unit. If she finds any of the similar cases of discrimination among the assigned patients, she should ask the unassigned staff right there and then the reason for not attending the patient in the absence of the fellow assigned staff. A counselling session could also work best for the staffs who are only work-oriented rather than patient-oriented. In addition to this, Head Nurses themselves should not be discriminating their service lines from the others in the same unit, and also helping the fellow management team to get the work done. This thing would help the subordinates to see the helping hands tradition on upper level of the authority and implement the same doing on their level. If we talk on management level, we can propose that same service line should be combined in a unit so that there could be a uniformity in the specialty. For instance, if $\mathrm{C} 1$ is having three service lines at a same time, we should make this as one service line unit as either neurology, orthopedic or ENT. This would enable the subordinates to work with same expertise. This might not be applicable in a short run, but could be implemented in a long run.

In conclusion, nurses are the main agent that is responsible for patient's care. Whenever they start discriminating between their patients and other fellow nurse patients, nursing care aspects get skipped in between.

\section{REFERENCES}

1. Clarke, S. P., \& Donaldson, N. E. (2008). Nurse staffing and patient care quality and safety. In Patient Safety and Quality: An Evidence-based Handbook for Nurses.

2. Nursing and Patient Safety. (2019). Retrieved from http://www.psnet.ahrq.gov/primer/nursing-and-patient-safety

3. Kim, K., Yoo, M. S., \& Seo, E. J. (2018). Exploring the influence of nursing work environment and patient safety culture on missed nursing care in Korea. Asian Nursing Research, 12(2), 121-126. doi:10.1016/j.anr.2018.04.003

4. Kieft, R. A., de Brouwer, B. B., Francke, A. L., \& Delnoij, D. M. (2014). How nurses and their work environment affect patient experiences of the quality of care: A qualitative study. BMC Health Services Research, 14(1), 249. https://doi.org/10.1186/1472-6963-14-249

5. The Nursing Shortage and How It Will Impact Patient Care. (2018, June 15). Bradley University Online. https://onlinedegrees.bradley.edu/blog/the-nursing-shortage-and-how-it-will-impact-patient-care/

6. Gutsan, E., Patton, J., \& Willis, W. K. (n.d.). Burnout syndrome and nurse-to-patient ratio in the workplace. 21.

7. Mudallal, R. H., Othman, W. M., \& Al Hassan, N. F. (2017). Nurses' Burnout: The Influence of Leader Empowering Behaviors, Work Conditions, and Demographic Traits. Inquiry: A Journal of Medical Care Organization, Provision and Financing, 54. https://doi.org/10.1177/0046958017724944

8. Registered Nurses' Association of Ontario. (2017). Developing and sustaining safe, effective staffing and workload practices (2nd ed.). Toronto, ON: Registered Nurses' Association of Ontario.

9. Amanchukwu, R. N., Stanley, G. J., \& Ololube, N. P. (2015). A review of leadership theories, principles and styles and their relevance to educational management. Journal of Management, 5(1), 6-14. doi: 10.5923/j.mm.20150501.02

CITATION: Komal Abdul Rahim (2021). Division of Nurse Staffing and Compromised Patient Care. South Asian Res J Nurs Health Care, 3(1): 5-6. 